UDC 330.16

LBC 60.561 .2

\title{
SOCIAL STATUS AND ITS IMPACT ON CONSUMER BEHAVIOR OF ACTOR IN THE MARKET OF TOURIST SERVICES
}

\author{
Elena V. Guryeva \\ Volgograd State University, Volgograd, Russian Federation
}

\begin{abstract}
The article discusses the theoretical aspects of studying the consumer practices of the Russians in the market of tourist services and hypotheses about the nature of the impact of social status on the consumer practices of actors in tourism are tested. The results of the questionnaire survey of consumers of tourist services in the Volgograd region in 2017 (sample size $n=220$ people) are presented. The sample was targeted, customers of travel agencies, hotels were interviewed. There are three groups of actors in terms of economic income: highincome, middle-income, low-income consumers. Each of the selected groups demonstrates specific types of consumer practices. Representatives of the high-income group relax up to 4 times a year and choose exotic and elite tourist products, individual tours and demonstrate a stable opinion that foreign travel is more prestigious and better in quality than domestic tourism. Representatives of the middle class have rest at average 2 times a year, they are interested in trips not only for relaxation purposes but for expansion of Outlook through excursions and visiting of sights, seek to receive the maximum number of new impressions and new knowledge. In low-income group of tourists requirements for the tour are minimal, frequency of rest 1-2 times a year. The results obtained on the specifics of consumer behavior of the Russians allow us to draw the following conclusions: the development of consumer behavior in modern Russia is influenced by the following factors: historical (weak development of the domestic tourism sector); natural (geographical features of the country); socio-economic (drop in income, the emergence of cheap foreign tours, the high cost of domestic travel); socio-political (economic sanctions, aggravation of relations with some countries); cultural (consumer education).
\end{abstract}

Key words: social status, the needs of tourist consumption practices, tourism, consumer, income.

УДК 330.16

ББК 60.561 .2

\section{СОЦИАЛЬНЫЙ СТАТУС И ЕГО ВЛИЯНИЕ НА ПОТРЕБИТЕЛЬСКОЕ ПОВЕДЕНИЕ АКТОРА НА РЫНКЕ ТУРИСТСКИХ УСЛУГ}

\author{
Елена Владимировна Гурьева \\ Волгоградский государственный университет, г. Волгоград, Российская Федерация
}

\begin{abstract}
Аннотация. В данной статье рассматриваются теоретические аспекты изучения потребительских практик россиян на рынке туристских услуг и проверяются гипотезы о характере влияния социального статуса на - потребительские практики акторов в сфере туризма. В статье представлены результаты анкетного опроса 후 потребителей туристских услуг в Волгоградской области в 2017 г. (объем выборки $n=220$ чел.). Выборка носила целенаправленный характер, были опрошены клиенты туристических фирм, отелей. Выделены три группы акторов по уровню экономических доходов: высокообеспеченные, среднеобеспеченные, малообес\% печенные потребители. Каждая из выделенных групп демонстрирует специфические типы потребительских практик. Представители высокообеспеченной группы отдыхают до 4 раз в год и выбирают экзотические и элитные туристские продукты, индивидуальные туры, демонстрируют устойчивое мнение о том, что зару() бежные путешествия престижнее и лучше по качеству, чем внутренний туризм. Представители среднего
\end{abstract}


класса отдыхают в среднем 2 раза в год, они заинтересованы в поездках не только в целях релаксации, но для расширения кругозора через экскурсии и посещение достопримечательностей, они стремятся получить максимальное количество новых впечатлений и новых знаний. У малообеспеченной группы туристов требования к туру минимальны, периодичность отдыха 1-2 раза в год. Полученные результаты о специфике потребительского поведения россиян позволяют сделать следующие выводы. На развитие потребительского поведения в современной России влияют следующие факторы: исторические (слабая развитость отечественной туристической сферы); естественные (географические особенности страны); социоэкономические (падение уровня доходов населения, появление дешевых заграничных туров, высокая стоимость внутренних поездок); социополитические (экономические санкции, обострение отношений с некоторыми странами); культурные (уровень образования потребителей).

Ключевые слова: социальный статус, потребности туриста, потребительские практики, сфера туризма, потребитель, уровень доходов.

Потребительское поведение - это система социальных действий, направленных на принятие актором потребительских решений. Процесс принятия решений связан с осознанием ценности товаров и услуг, формируемой их объективными характеристиками и субъективными предпочтениями индивидов, которыепридают данным товарам и услугам дополнительный смысл. Разрабатывая концепцию «общества потребления», Ж. Бодрийяр интерпретировал общество потребления как совокупность отношений между индивидами в условиях рынка, где индивидуальное потребление играет ведущую роль [2, с. 5].

Однако при оценке товаров и услуг нельзя отрицать влияние социального окружения. У Ж. Бодрийяра потребление - это регулярный акт манипуляции знаками, а система потребительских товаров проходит через призму кода сигнификации, который контролирует как предметы, так и индивидов. Предметы потребления становятся одними из частей знаковой системы. С помощью средств рекламы происходит мифологизация окружающего мира, заменяющая потребителям реальность. Товары и услуги утрачивают свою реальную материальную и функциональную значимость и воспринимаются по символическим характеристикам, учитывая только знаковую стоимость.

В данном случае потребление становится формой социального контроля, с помощью которого в обществе формируется согласованность благодаря осознанию индивидами важности для них игры по правилам потребительного общества. Индивиды присоединяются к определенной группе через потребление схожих знаков $[1 ; 10]$. В данной модели потребление является основой вертикальной и гори- зонтальной социальной стратификации. В обществе потребления исследование социальной идентичности - это осознание индивидами своего места в обществе, отнесение себя к определенным социальным группам, что подразумевает определенную модель потребления, образа жизни, соответствия ожиданиям других индивидов.

М. Дуглас и Б. Ишервуд, напротив, обосновывая культурно-антропологический подход, говорят о нейтральности товара и социальности потребления данного товара [13]. В культурно-антропологическом подходе потребление воспринимается в качестве процесса потребления благ, сущность потребления определяется с помощью раскрытия его функций. М. Дуглас и Б. Ишервуд выделяют две главные функции потребления:

1. Потребление формирует и демонстрирует категории культуры. В отличие от экономического подхода потребитель не рассматривается в аспекте индивидуальности и независимости принятия решения. Товары и услуги определяют релевантность конкретных социальных категорий в данной культуре и делают их стабильными определенным способом.

2. С помощью потребления товаров и услуг формируются и поддерживаются социальные связи. Таким образом, помимо индивидуального потребителя, существует большое количество разнообразных взаимосвязей (семейные, дружеские, рабочие и т. д.).

В рамках культурно-антропологического подхода главная функция потребления определяется не в способности удовлетворять потребности, а в способности создавать смысл. Авторами данного подхода товары и услуги воспринимаются как невербальное средство возможностей индивида [13, р. 53]. 
С. Майлз предложил разделить понятие потребления и консюмеризма (потребительства), синтезируя идеи концепции общества потребления и культурно-антропологического подхода. В данной интерпретации потребление определяется как набор социальных, экономических, культурных практик, которые признают законный статус капитализма совместно с идеологией потребительства в глазах миллионов людей $[15$, р. 27]. Консьюмеризм является сложной категорией в отличие от рутинного процесса покупки и потребления благ. С помощью изучения консьюмеризма можно приблизится к пониманию всех взаимосвязей, лежащих в основе потребления.

T. Веблен в своих работах отмечал факт подтверждения потребителем благ своего статуса при выборе определенного вида товаров или услуг [3, с. 108]. Фундаментальные основы изучения природы человеческих потребностей заложил А. Маслоу, по мнению которого специфическая черта человека состоит в том, что на протяжении всего своего существования он непрерывно чего-то желает [9, с. 51]. При этом, как правило, достичь полного удовлетворения не удается. Исключение составляет лишь краткосрочный эффект. Кроме того, ученый выдвинул идею о том, что все человеческие потребности систематизированы в определенную иерархическую структуру и располагаются по степени преобладания. Так, среди них выделяются такие виды потребностей, как физиологические, потребность в самосохранении, социальные, потребность в уважении и потребность в самореализации.

Интересно, что перечисленные потребности можно спроецировать на сферу туризма. Раскрывая каждую группу потребностей с учетом их реализации в связи с приобретением туристских услуг по А. Маслоу, получим следующую картину:

- физиологические потребности (рекреационно-оздоровительное воздействие сферы туризма на человеческий организм);

- потребности в безопасности (отсутствие опасностей по дороге к месту отдыха, предоставление медицинских услуг по страховке, обеспечение высокого уровня безопасности на конкретном объекте и др.);

- потребность в любви и принадлежности (поездка с семьей на отдых, активизация вовлечения отдыхающих в различные программные мероприятия, направленные на выстраивание благоприятных социальных связей между всеми участниками и организаторами);

- потребности в уважении (чувственное восприятие туристической поездки, передача положительных эмоций и полученного опыта своему близкому окружению от потребления тура);

- потребность в самоактуализации (желании проявить свои способности с целью достижения высоких результатов).

Таким образом, анализируя иерархию потребностей А. Маслоу, можно сформулировать концептуальный вывод о направленности туристской индустрии на реализацию базовых потребностей индивида и потребностей более высокого уровня.

Особый интерес вызывает исследование двухфакторной теории Ф. Герцберга в контексте рассмотрения сферы туризма. Эта теория основывается на выделении двух укрупненных групп потребностей, которые формируют удовлетворенность либо неудовлетворенность индивида. К ним относятся следующие:

- гигиенические факторы (атмосферные);

- факторы актуализации.

К первой группе рассматриваемых факторов целесообразно отнести такие показатели туристских услуг, которые, как правило, включаются в стандартный туристический пакет. Их наличие воспринимается как должное и тем самым не приводит к повышению удовлетворенности туристским продуктом. В случае отсутствия такой услуги или при ее неудовлетворительном качестве она в разы снижает уровень потребительской удовлетворенности. К таким параметрам следует отнести следующие:

- чистота;

- безопасность жизни и имущества;

- возможность получения медицинского обслуживания и др.

Вторая группа факторов придает чувство удовлетворенности и приводит к личностному самосовершенствованию. Причем данный эффект от туристской услуги носит длительный характер. Иными словами, их базовое предназначение сводится к повышению потребительской удовлетворенности полученной 
услугой в сфере туризма. К данным факторам целесообразно отнести следующие:

- формирование индивидуальной программы поездки;

- предоставление памятных сувениров на бесплатной основе;

- обеспечение дополнительными оздоровительными процедурами сверх оплаченного пакета;

- возможность участия в культурных мероприятиях.

Следует подчеркнуть, что туристические фирмы в целях поддержания своей конкурентоспособности должны на регулярной основе производить оценку перечисленных факторов. При этом целесообразно принимать во внимание различные социальные группы отдыхающих. Такой подход позволит своевременно выявить скрытые резервы, а также разработать оригинальные программы для туристов.

В контексте социологии потребления изучаются феномены, которые подвержены влиянию социальной структуры и культуры конкретного общества. Этнометодология, автором которой является американский социолог Г. Гарфинкель, оказала большое влияние на формирование социологического подхода к интерпретации и анализу потребительского поведения. Внимание исследователей данного направления сосредоточено на изучении обыденных норм, смыслов языка, формирования потребительских привычек в рамках повседневных коммуникаций. В основе методов этнографических исследований лежат идеи этнометодологии (наблюдения, дневники, моделирование дискурса и др.). Например, Г. Гарфинкель показывает, что практики закрепляются в процессе осуществления совокупности однообразных, рутинных действий [4, с. 9]. Исходя из данного тезиса, можно сформулировать следующее определение «практик». Под ними целесообразно понимать повседневную деятельность человека. Иными словами, эта деятельность включает все, что происходит с отдельным человеком каждый день, например, труд, отдых, бытовое существование и др.

Большую роль играет позиция И.В. Глушко, который выделяет две полярные стороны в структуре практики, а именно [5, с. 33]:
- внутреннюю (предполагает волевые и духовные усилия личности);

- внешнюю (выступает инструментально-предметное отношение человека к окружающему миру).

По мнению автора, различные внешние формы проявления подвергаются процессу институализации и превращаются в достаточно устойчивые единицы, которые оказывают выраженное влияние на социальную жизнь. Внутренняя часть не включается в социокультурные нормы. Здесь происходит формирование отклоняющихся, в некоторой степени протестных проявлений социальной активности. О.В. Лысикова показывает, как социальные практики способствуют возникновению новых идентичностей, которые приводят к восприятию собственной целостности, позволяют реагировать максимально гибко на изменения, происходящие в социуме, использовать новый опыт [7, с. 33].

Л.П. Кураков отмечает длительность и непрерывность существования потребностей на всем протяжении развития человечества. Чем более развитым становилось человечество, тем сильнее менялось качество потребностей и его набор, что приводило к изменениям условий и требований к необходимым обществу и отдельной личности услугам и товарам. Л.П. Кураков в своих работах делает акцент на особенность в развитии человеческих потребностей и человеческой деятельности: появление новых видов потребностей ведет к возникновению новых видов человеческой деятельности, которые, в свою очередь, инициируют новые потребности, что продолжается до бесконечности [6, с. 158].

В сфере туризма естественные потребности не являются единственно возможными. Они преломляются в зависимости от силы влияния вновь появившейся социальной среды. Это означает, что дефиницию «потребительские практики» в рамках изучения сферы туризма целесообразно рассматривать как единовременные или регулярные действия лица, которые ориентированы на приобретение и использование продуктов туристического сегмента с целью реализации собственных личностных потребностей.

Необходимо подчеркнуть, что осмысление туристского потребления осложняется 
особенностями этого вида услуг, так как данный вид потребления носит крайне неоднородный характер. Специфическая особенность потребительского поведения в сфере туризма заключается в том, что человек в случае вложения денежных средств в результате не получает определенную экономическую выгоду или товар, а получает удовлетворение своих потребностей, которое является нематериальным. Некоторые специалисты помимо традиционных свойств туристских услуг (изменчивость, неспособность к хранению, неразрывность потребления и производства, неосязаемость) выделяют и другие признаки, в частности ориентированность на разнообразие потребителей. Это утверждение означает, что разные категории туристов отличаются следующим:

- цель поездки;

- требования к туристским услугам;

- цена, которую туристы готовы заплатить.

Следует подчеркнуть, что для каждой социальной группы туристов характерен конкретный тип туристского рынка. Так, некоторые ученые применяют к анализу туристских услуг концепцию общественного блага в качестве инновационного подхода к исследованию их особенностей, согласно которой туристские услуги рассматриваются как смешанные блага. Это обусловлено двумя факторами: их исключительностью и конкурентоспособностью в потреблении. Кроме того, выступая смешанным благом, туристская услуга является объектом купли-продажи, то есть, иными словами, реализуется на коммерческих началах.

Помимо того, на потребительские практики оказывает влияние множество условий, факторов и предпосылок, которые в сумме составляют целую систему. На потребление туристских услуг в современном обществе воздействуют две группы факторов, носящих субъективный и объективный характер.

К объективной группе условий Е.В. Малышева относит [8, с. 88]:

- исторические предпосылки (слабая развитость отечественной туристической сферы, колоссальное воздействие процессов «перестройки» на туристическое поведение, ярко выраженный интерес старшего поколения к познавательному туризму);
- естественные факторы (возраст, пол, географические особенности страны, экологическая ситуация, особенности экологического сознания населения);

- социоэкономические условия (падение уровня доходов населения, появление более дешевых заграничных туров, высокая стоимость внутренних поездок, возникновение зажиточных слоев населения, ориентированных на дорогостоящие туристические поездки в дальнее зарубежье);

- социополитические особенности (вхождение все большего числа стран в Европейский союз, обострение отношений с некоторыми странами, политика, стимулирующая эмиграцию и внешний ознакомительный туризм);

- культурные условия (этническая специфика региона или страны, уровень образования потребителей).

Данные условия являются равнозначными для потребителя при выборе туристского продукта, способными повлиять на его предпочтения при определенных условиях. Детерминирующее влияние на выбор туристского продукта оказывает уровень дохода населения и, соответственно, принадлежность к определенной социальной группе, социальный статус актора.

Социальный статус актора складывается из множества компонентов и оказывает непосредственное воздействие практически на все стороны его жизни и деятельности начиная от потребностей в еде и одежде и заканчивая удовлетворением культурных и духовных нужд. Сегмент туризма не является исключением, поскольку путешествие определяет социальный статус как способ проведения свободного времени.

В интерпретацию понятия «социальный статус» внесли существенный вклад М. Вебер, Т. Парсонс, Д. Локвуд и др. К. Маркс в социально-классовой теории выдвинул одномерную классовую концепцию общества, где принадлежность к социальному классу определяется согласно отношению индивида к средствам производства и основой структурирования общества является экономический критерий. Д. Локвуд и Д. Голдторп измеряют социальный статус тремя показателями: положением на рынке, положением на работе и статусным положением [14, p. 481-505]. Ста- 
тусное положение - социальная репутация, которая зависит от положения индивида внутри сообщества. Сегодня понятие трактуют как жизненный стиль, авторитет личности, престиж, репутацию в рамках социальной стратификации, однако в настоящее время в российской социологии отсутствует единый концептуальный подход в определении социального статуса индивида, критериев социальной структуры общества [11, с. 83]. Показатели, по которым определяется социальный статус, могут быть следующими:

- работа;

- проводимый досуг;

- семейное положение;

- место жительства;

- место в иерархии политической системы;

- собственность;

- уровень потребления.

Это позволяет выделять социальные группы в зависимости от набора характеристик. Таким образом, социальный статус определяется с помощью социальных функций, которые выполняет индивид при взаимодействии с другими членами общества. Социальным статусом обозначается общее положение социальной группы или личности в обществе в целом, которое сопряжено с предписанной совокупностью обязанностей и прав. Перспективным для анализа потребительского поведения акторов является понятие «достигаемый статус», то есть социальный статус индивида, который приобретается благодаря личным усилиям и способностям личности - профессия, образование, должность, удачный брак и др.

Достигаемые статусы преобладают в социуме, где наблюдается высокий социально-экономический рост. Благодаря достигаемым статусам социальные структуры заполняются более справедливо, поскольку учитывают личные качества, профессионализм, индивидуальные способности и особенности человека, что приводит к эффективному функционированию в рамках статуса.

Основу стратификации в любом обществе формирует иерархия статусов. Престижность статусных групп формируется обществом с помощью оценки социальной значимости статуса исходя из общественного мнения и культуры. Именно поддержание стату- са и престижа оказывает важное влияние на поведение человека и его потребительские практики в сфере туризма. С помощью знания социального статуса личности можно заблаговременно предсказать поведение и большинство действий индивида, исходя из его качеств. Ожидаемое поведение индивида, связанное с обладающим им статусом, в социологии называют социальной ролью.

Существенное влияние на социальный статус индивида оказывает его материальное положение, в понятие которого, помимо уровня благосостояния, включены также и уровень образования, доступ к власти, профессия и др. Социальный статус, обобщающий ряд критериев, является индексом социальной позиции. Длительное время считалось, что социальный статус непосредственно связан с осуществляемой профессиональной деятельностью и занимаемой должностью. Однако позже работа как основной социальный признак уступила такому фактору, как досуг. А.Б. Фенько, опираясь на работы Д. Урри, утверждает, что одним из признаков социального статуса стал туризм. В случае отказа человека от потребления туристских услуг положение в обществе для данного индивида будет потеряно [12, с. 126].

Социальный статус по уровню доходов, наличию собственности традиционно делится на высокообеспеченную (высший класс, «элита»), среднеобеспеченную («средний класс»), малообеспеченную группу и группу людей, находящихся за чертой бедности. К высокообеспеченной группе относятся люди, имеющие в собственности имущество в виде элитной недвижимости, люксовых автомобилей, неограниченные в приобретении объектов недвижимости, автомобилей, антиквариата. Среднеобеспеченную группу формируют люди, имеющие в собственности недвижимость и/или автомобиль, способные приобрести автомобиль, но испытывающие затруднения с покупкой недвижимости, часто совершающие покупки без дополнительных заемных средств. Представители малообеспеченной группы населения не имеют возможности приобрести в собственность недвижимость, автомобиль, часто пользуются дополнительными заемными средствами, крайне редко совершают покупки. Основная часть доходов у представителей малообеспеченной группы 
уходит на приобретение продуктов питания и одежды. Представители группы, находящейся за чертой бедности, не имеют в собственности недвижимости и прочего имущества, весь доход уходит на приобретение продуктов питания.

По результатам социологического исследования, проведенного методом анкетного опроса среди потребителей туристских услуг в Волгоградской области в 2017 г. (объем выборки $n=220$ чел.), были выделены три социальные группы населения по уровню доходов: высокообеспеченная (7,6 \% выборочной совокупности), среднеобеспеченная (78,3\%), малообеспеченная (14,1\%). Все респонденты являются клиентами туристических фирм, отелей, в которых они заполняли анкеты.

Согласно исследованию, наиболее предпочитаемыми направлениями у среднеобеспеченной группы были Тайланд (62,1 \%), Россия $(54,7 \%)$, ОАЭ $(27,8 \%)$, также были отмечены Доминикана (3,7 \%), Мальдивы $(3,1 \%)$, Индонезия $(1,2 \%)$. Высокообеспеченная группа отмечала страны Европы (слишком большая группировка - вся Европа) $(86,7 \%)$, Мальдивы $(73,7$ \%), Сейшелы (53,4 \%), США (23,5 \%), Фиджи (13,2 \%), ЮАР $(4,4 \%)$. Малообеспеченная группа в большинстве предпочитала Россию $(97,6$ \%). Таким образом, можно сделать вывод о том, что представители высокообеспеченной группы выбирают экзотические и элитные туристические продукты, индивидуальные туры, тем самым стремятся показать свою исключительность и свой высокий социальный статус. Выбор тура зависит от месторасположения и возможности его приобретения: чем дороже тур и дальше от постоянного места проживания, тем элитнее курорт.

При выборе места проведения отдыха у высокообеспеченной и среднеобеспеченной групп туристов сложилось устойчивое мнение о том, что зарубежные путешествия престижнее и лучше по качеству, чем внутренний туризм. При выборе путевки туристы данных социальных групп готовы платить больше за зарубежное путешествие в престижном месте.

Согласно полученным данным высокообеспеченная группа туристов при постановке основных целей путешествия выбирала смену впечатлений $(82,3$ \%), посещение кра- сивых мест природы (73,5 \%), попробовать экзотическую (местную) кухню (52,9 \%). Среднеобеспеченная группа при ответе на данный вопрос анкеты указала: смена впечатлений (71,8 \%), искупаться в море, океане $(69,2 \%)$, знакомство с достопримечательностями места отдыха и его культурой (52,2 \%), шоппинг $(23,9 \%)$. Малообеспеченная группа в целях путешествия выбирает: искупаться в море, океане $(89,1 \%)$, смена впечатлений $(51,2 \%)$.

Качество кухни у высокообеспеченной группы туристов, помимо смены впечатлений и посещения красивых мест природы, является одним из основных параметров при выборе места отдыха. Кухня должна обеспечивать экзотические вкусы и гастрономические предпочтения представителей данной социальной группы. Ассортимент еды должен быть разнообразным, приготовленным профессиональными шеф-поварами, учитывать все запросы и предпочтения туристов. Для представителей среднеобеспеченной и малообеспеченной групп основными целями являются возможность искупаться в море, позагорать и просто отдохнуть на пляже. Представители среднего класса заинтересованы в поездке и расширении своего кругозора через экскурсии и посещение достопримечательностей, стремясь получить максимальное количество новых впечатлений и новых знаний. Требования к еде у малообеспеченной группы минимальны - питание, доступное по цене и предоставляемое в достаточном количестве.

При выборе туристского продукта представители среднего класса опираются на рекомендации знакомых и друзей $(87,3$ \%), малообеспеченную группу интересует стоимость тура (93,4 \%), высокообеспеченную - уровень сервиса и облуживания (73,7 \%). При выборе туристского продукта представители среднего класса стремятся следовать моде, подражать своим знакомым и друзьям для поднятия собственного статуса, маскируя отсутствие необходимого уровня достатка.

Большое количество туристов из высокообеспеченной группы предпочитают туризм с минимальным количеством людей на территории зоны отдыха, уходя от публичности, встреч со своими знакомыми и соотечественниками $(77,4$ \%). Среднеобеспеченная группа 
стремится расширить круг знакомств при путешествии $(51,8 \%)$. Малообеспеченная группа не придает особого значения ни расширению круга знакомств $(3,2 \%)$, ни избеганию встреч с соотечественниками (1,6 \%). Среднеобеспеченные туристы, в отличие от высокообеспеченных $(23,5 \%)$ и малообеспеченных туристов $(36,7 \%)$, во время отдыха на курорте активно пользуются социальными сетями (79,3\%), размещая свои фотографии, видеозаписи для привлечения к себе дополнительного внимания. Демонстративное поведение дает возможность представителям среднеобеспеченной группы поднять свой социальный статус с помощью путешествия, показав свой уровень дохода и возможность траты денег на развлекательные услуги, туристические продукты в экзотические места отдыха.

При выборе места отдыха и отеля высокообеспеченная группа населения ориентирована на бренд компании, предоставляющей туристский продукт (85,3%). Чем престижнее и известнее в мире бренд, тем больше вероятность предпочтения данного продукта. Это связано с уверенностью туристов в качестве, а также с возможностью демонстрации своего социального статуса.

Туристы высокообеспеченной группы отдают предпочтение отелям категории «пять звезд» $(97,1 \%)$, клубным отелям $(54,4 \%)$ с эксклюзивными услугами и индивидуальным сервисом. Высокообеспеченные туристы отмечают в предпочтениях индивидуальное обслуживание (66,1\%), трансфер на люксовых автомобилях (36,7 \%), предоставление услуг индивидуального гида-переводчика $(25,0 \%)$.

Туристы среднеобеспеченной группы населения при выборе туристического продукта отдают предпочтение типу питания по системе «Все включено» $(89,1 \%)$, их интересует наличие бассейна на территории отеля $(65,7 \%)$, условия для отдыха с детьми $(48,1 \%)$, наличие экскурсии в составе тура $(13,2 \%)$.

В отличие от туристов высокообеспеченной и среднеобеспеченной групп туристы малообеспеченной группы при выборе туристического продукта предпочитают наличие скидок (78,3 \%), близкое расположение к основному месту проживания (67,9\%), наличие в отеле русскоговорящего персонала (48,7 \%).
Таким образом, результаты эмпирического исследования позволили раскрыть специфику потребительских практик отдельных социальных групп Волгоградской области. Выявлено, что социальный статус выступает одним из основных факторов, влияющих на потребительские практики. Уровень доходов туристов является решающим элементом при выборе туристского продукта. Так, чем выше материальное состояние лица, направляющегося на отдых, тем большие требования он предъявляет. Напротив, основная масса людей, которые относятся к малообеспеченной группе, не испытывают повышенных ожиданий от туристических поездок.

Обязательным условием для демонстрации своего статуса в обществе для высокообеспеченной и среднеобеспеченной групп населения является туризм с максимальным количеством услуг и индивидуальным подходом. При формировании туров следует учитывать особенности поведения различных категорий населения в зависимости от их уровня доходов. Это поможет сформировать туристические пакеты для привлечения высокообеспеченной и среднеобеспеченной групп населения, делая акцент на престижности потребления, с целью развития внутреннего и въездного туризма в Российской Федерации.

\section{СПИСОК ЛИТЕРАТУРЫ}

1. Ахметова, Э. И. Социально-психологический аспект потребительского поведения (на примере сельских жителей) / Э. И. Ахметова // Историческая и социально-образовательная мысль. 2013. - № 5 (21). - С. 169-173.

2. Бодрийяр, Ж. Общество потребления. Его мифы и структуры / Ж. Бодийяр. - М. : Республика, 2006. $-269 \mathrm{c}$.

3. Веблен, Т. Теория праздного класса / Т. Веблен. - М. : Прогресс, 1984. - 367 c.

4. Гарфинкель, Г. Исследования по этнометодологии / Г. Гарфинкель. - СПб. : Питер, 2007. $335 \mathrm{c}$.

5. Глушко, И. В. Осмысление феномена социальных практик и возможностей их развития / И. В. Глушко // Общество, философия, история, культура. - 2011. - Вып. 1-2. - С. 33-36.

6. Кураков, Л. П. Экономическая теория : учеб. пособие / Л. П. Кураков. - М. : МПСИ, МОДЭК, 2007. $1072 \mathrm{c}$. 
7. Лысикова, О. В. Социальные практики российских туристов: предпочтения стран и городов посещения / О. В. Лысикова // Вестник Томского государственного университета. Философия. Социология. Политология. -2012 . - № 1 (17). - С. 31-45.

8. Малышева, Е. В. Потребительские практики в сфере туризма: когортный анализ : дис. ... канд. социол. наук / Малышева Елена Вячеславовна. Казань, 2014. -275 с.

9. Маслоу, А. Мотивация и личность / А. Маслоу. -СПб. : Питер, 2003. -352 c.

10. Тарасова, Т. В. Общество потребления как современная парадигма изучения потребительского поведения / Т. В. Тарасова // Научное обозрение. -2012 . - № 6. - С. 11-18.

11. Уксуменко, А. А. Туризм как способ социальной дифференциации / А. А. Уксуменко, И. С. Маркова // Ученые записки Комсомольского-на-Амуре государственного технического университета. - 2011. - Т. 2, № 6. - С. 83-85.

12. Фенько, А. Б. Туризм как показатель социального статуса / А. Б. Фенько // Социологические исследования. - 2007. - № 2. - С. 125-131.

13. Douglas M. The World of Goods. Towards an Anthropology of Consumption / M. Douglas, B. Isherwood. - L. : Routledge, 1996. - $169 \mathrm{p}$.

14. Goldthorpe, J. H. Class analysis and the reorientation of class theory: the case of persisting differentials in educational attainment / J. H. Goldthorpe // The British Journal of Sociology. - 1996. - Vol. 47, № 3. - P. 481-505.

15. Miles, S. Consumerism as a way life/S. Miles. L. : Sage, 1998. -174 p.

\section{REFERENCES}

1. Akhmetova E.I. Sotsialno-psikhologicheskiy aspekt potrebitelskogo povedeniya (na primere selskikh zhiteley) [Socio-Psychological Aspect of Consumer Behavior (the Case of Rural Residents)]. Istoricheskaya $i$ sotsialno-obrazovatelnaya mysl [Historical and Socio-Educational Thought], 2013, no. 5 (21), pp. 169-173.

2. Baudrillard J. Obshchestvo potrebleniya. Ego mify $i$ struktury [The Consumer Society: Myths and Structures]. Moscow, Republic Publ., 2006. 269 p.

3. Veblen T. Teoriya prazdnogo klassa [The Theory of the Leisure Class]. Moscow, Progress Publ., $1984.367 \mathrm{p}$.
4. Garfinkel H. Issledovaniya po etnometodologii [Studies in Ethnomethodology]. Saint Petersburg, Piter Publ., 2007.335 p.

5. Glushko I.V. Osmyslenie fenomena sotsialnykh praktik i vozmozhnostey ikh razvitiya [Interpreting the Phenomenon of Social Practices and Possibilities of Their Development]. Obshchestvo, filosofiya, istoriya, kultura [Society, Philosophy, History, Culture], 2011, no. 1-2, pp. 33-36.

6. Kurakov L.P. Ekonomicheskaya teoriya: ucheb. posobie [Economic Theory: Textbook]. Moscow, MPSI, MODEK Publ., 2007. 1072 p.

7. Lysikova O.V. Sotsialnye praktiki rossiyskikh turistov: predpochteniya stran i gorodov poseshcheniya [Social Practice of Russian Tourists: Preferences of Countries and Cities]. Vestnik Tomskogo gosudarstvennogo universiteta. Filosofiya. Sotsiologiya. Politologiya [Science Journal of Tomsk State University. Philosophy. Sociology. Political Science], 2012, no. 1 (17), pp. 31-45.

8. Malysheva E.V. Potrebitelskie praktiki v sfere turizma: kogortnyy analiz: dis. ... kand. sotsiol. nauk [Consumption Practices in Tourism: a Cohort Analysis. Cand. sociol. sci. diss.]. Kazan, 2014. 275 p.

9. Maslow A. Motivatsiya i lichnost [Motivation and Personality]. Saint Petersburg, Piter Publ., 2003. $352 \mathrm{p}$.

10. Tarasova T.V. Obshchestvo potrebleniya kak sovremennaya paradigma izucheniya potrebitelskogo povedeniya [The Consumer Society as a Modern Paradigm to Study the Consumer Behavior]. Nauchnoe obozrenie, 2012, no. 6, pp. 11-18.

11. Uksumenko A.A., Markova I.S. Turizm kak sposob sotsialnoy differentsiatsii [Tourism as a Way of Social Differentiation]. Uchenye zapiski Komsomolskogona-Amure gosudarstvennogo tekhnicheskogo universiteta, 2011, vol. 2, no. 6, pp. 83-85.

12. Fenko A.B. Turizm kak pokazatel sotsialnogo statusa [Tourism as an indicator of social status]. Sotsiologicheskie issledovaniya, 2007, no. 2, pp. 125-131.

13. Douglas M., Isherwood B. The World of Goods. Towards an Anthropology of Consumption. London, Routledge, 1996. $169 \mathrm{p}$.

14. Goldthorpe J.H. Class analysis and the reorientation of class theory: the case of persisting differentials in educational attainment. The British Journal of Sociology, 1996, vol. 47, no. 3, pp. 481-505.

15. Miles S. Consumerism as a way of life. London, Sage, 1998. 174 p. 


\section{СОЦИОЛОГИЯ И СОЦИАЛЬНЫЕ ТЕХНОЛОГИИ}

\section{Information about the Author}

Elena V. Guryeva, Senior Lecturer, Department of Archaeology, Foreign History and Tourism, Volgograd State University, Prosp. Universitetsky, 100, 400062 Volgograd, Russian Federation, gurlena@rambler.ru.

\section{Информация об авторе}

Елена Владимировна Гурьева, старший преподаватель кафедры археологии, зарубежной истории и туризма, Волгоградский государственный университет, просп. Университетский, 100, 400062 г. Волгоград, Российская Федерация, gurlena@rambler.ru. 